\title{
VIOLÊNCIA INTRAFAMILIAR E AS REPERCUSSÕES PARA SAÚDE DA MULHER: COMPREENDENDO A HISTÓRIA DE ANTÔNIA
}

Intrafamily violence and the repercussions for women's health: Understanding the story of Antonia

Violencia intrafamiliar y las repercusiones para la salud de la mujer: Comprensión de la historia de Antônia

\author{
Jaqueline Rodrigues Stefanini \\ Universidade de São Paulo \\ Berenice Juan-Martínez \\ Universidad del Papaloapan \\ Débora Tatiane Góes Silva \\ Clínica Sintaxe Pronto Atendimento Psicológico \\ Marciana Gonçalves Farinha \\ Universidade Federal de Uberlândia
}

\begin{abstract}
RESUMO
O presente estudo tem como objetivo compreender a partir da perspectiva bioecológica as diferentes vivências de violência e suas repercussões para a vida de Antônia. Trata-se de um estudo de caso, visando a investigação de um fenômeno em profundidade. Os dados transcritos foram obtidos por meio de uma entrevista semi-estruturada. Para a discussão do estudo de caso foi utilizado o aporte teórico-metodológico das contribuições do modelo bioecológico do desenvolvimento humano de Urie Bronfenbrenner. Neste trabalho constatou-se que Antônia vivenciou diversas formas de violência intrafamiliar, nas diferentes fases do seu desenvolvimento. As repercussões dessas vivências foram relacionadas à saúde sexual e reprodutiva, e ao sofrimento mental, com o desencadeamento de sintomas de estresse pós-traumático.
\end{abstract}

Palavras-chave: Violência Doméstica; Exposição à Violência; Desenvolvimento Humano; Saúde da Mulher.

\begin{abstract}
The present study aims to understand from the bioecological perspective the different experiences of violence and its repercussions for the life of Antonia. This is a case study, aimed at investigating a phenomenon in depth. The transcribed data were obtained through a semi-structured interview. For the discussion of the case study the theoretical-methodological contribution of the contributions of the bioecological model of human development of Urie Bronfenbrenner was used. In
\end{abstract}


this work it was verified that Antônia experienced several forms of intrafamily violence, in the different stages of its development. The repercussions of these experiences were related to sexual and reproductive health, and to mental suffering, with the onset of symptoms of posttraumatic stress.

Keywords: Domestic Violence; Exposure to Violence; Human Development; Women's Health

\section{RESUMEN}

El presente estudio tiene como objetivo comprender a partir en la perspectiva bioecológica las diferentes vivencias de violencia y sus repercusiones para la vida de Antônia. Se trata de un estudio de caso, buscando la investigación de un fenómeno en profundidad.

Para la discusión del estudio de caso se utilizó el aporte teórico-metodológico de las contribuciones del modelo bioecológico del desarrollo humano de Urie Bronfenbrenner. En este trabajo se constató que Antônia vivenció diversas formas de violencia intrafamiliar, en las diferentes fases de su desarrollo. A las repercusiones de estas vivencias se relacionaron con la salud sexual y reproductiva, y el sufrimiento mental, con el desencadenamiento de síntomas de estrés postraumático.

Palabras-clave: Violencia Doméstica; Exposición a la Violencia; Desarrollo Humano; Salud de la Mujer.

\section{INTRODUÇÃO}

A violência é um grave problema de saúde pública pelos danos físicos e psicológicos que provoca, traz em sua gênese uma multiplicidade de fatores ao envolver aspectos culturais, sociais, econômicos e políticos. Suas consequências geram prejuízos à saúde, afeta as relações familiares e sociais, e influenciam o desenvolvimento humano (Batista, Trigueiro, Lenardt, Mazza, \& Labronici, 2013; Oliveira et al., 2015). Dentre muitas formas de violência existentes na sociedade contemporânea, a violência intrafamiliar é cada vez mais frequente (Azevêdo \& Pereira, 2016; Martins, Rato, \& Marques, 2017).

A violência intrafamiliar se caracteriza pelo ato ou omissão que prejudique o bemestar, a integridade física e psicológica, e o direito ao desenvolvimento integral de um membro da família, sobretudo, crianças e adolescentes. É considerada violência intrafamiliar mesmo quando praticada fora do domicílio da vítima, quer tenha sido ocasionada pelos pais biológicos ou por pessoas que exerçam as funções parentais (Oliveira et al, 2015).

No âmbito das violências, existem os abusos físicos, manifestados por agressões corporais, inclusive com uso de objetos; os abusos psicológicos caracterizados por ações ou omissões que causem prejuízos à autoestima, à identidade, ao desenvolvimento da pessoa, inclui agressão verbal, ameaças e/ou abandono; o abuso sexual caracterizado pela relação de dominação-exploração baseada no poder, no qual uma pessoa faz uso de força física, coerção, intimidação ou influência psicológica, com uso ou não de armas ou drogas, obriga 
outra pessoa a ter, presenciar ou participar de alguma maneira de interações sexuais forçadas (Stefanini, Scherer, Scherer, Cavalin, \& Guazzelli, 2015; Oliveira et al, 2015; Azevêdo \& Pereira 2016).

A violência sexual contra a mulher constitui-se umas das mais antigas expressões da violência de gênero, além de representar uma grave violação de direitos humanos. As diversas expressões desse tipo de violência estão diretamente relacionadas à ideologia patriarcal, que demarca explicitamente os papéis e as relações de poder entre homens e mulheres, legitimando e alimentando a violência de gênero (Azevêdo \& Pereira, 2016; Silva \& Vagostello, 2017). Nesse contexto, as mulheres estão expostas à diversas formas de violência, incluindo a violência sexual, que acarreta às vítimas o sentimento de culpa, vergonha e prejuízos ao funcionamento sexual posterior. Existe ainda uma tendência das mulheres vítimas de violência sexual se envolverem em relacionamentos nocivos, dolorosos e insatisfatórios, com dificuldade de confiar e medo do abandono, que perpassam questões do desenvolvimento individual e transgeracionais (Camicia, Silva, \& Schmidt, 2016; Silva \& Vagostello, 2017). Intervenções especializadas são necessárias, por exemplo, em casos de estupros praticados por autores desconhecidos, em que é comum o desencadeamento de sintomas de estresse pós-traumático nas vítimas (Silva \& Vagostello, 2017).

A literatura descreve alguns aspectos relacionados à manutenção do ciclo da violência intrafamiliar, como a baixa escolaridade, dependência financeira, submissão ao homem e uso do álcool pelo agressor (Camicia et al., 2016; Ferreira \& Lopes, 2017). É neste cenário que a exposição à violência intrafamiliar causa danos psicológicos e físicos para a mulher violentada, assim como aos filhos e ao próprio agressor (Ferreira \& Lopes, 2017).

As múltiplas situações de violências, nas diferentes fases do desenvolvimento humano, também causam repercussões para a saúde. A violência afeta a saúde sexual e reprodutiva dessas mulheres com risco de contaminação por doenças sexualmente transmissíveis, incluindo HIVIAIDS e gestações indesejadas. O sofrimento mental, também é descrito na literatura, como consequência da vivência de situações de violência, com aumento do uso de álcool, tabaco e outras substâncias, depressão e isolamento social (Ferreira, Vasconcelos, Moreira Filho, \& Macena, 2016).

Entendemos que para compreensão da violência intrafamiliar, como um fenômeno multifatorial e complexo, é necessário um olhar interdisciplinar, com ênfase na pessoa, considerando a sua necessidade e multidimensionalidade. Dessa forma, o modelo Bioecológico de Urie Bronfenbrenner emerge como possibilidade de oferecer subsídios para conhecimento sobre essas dimensões que permeiam o desenvolvimento humano. Tal modelo apresenta elementos constitutivos da pessoa, em um processo dinâmico, no qual ocorre a interação entre o indivíduo e o ambiente em que está inserido (Batista et al., 2013; Justino, Cotonhoto, \& Nascimento, 2017). 
O desenvolvimento humano caracteriza-se pela acumulação de aquisições e conhecimentos a partir das experiências vividas e a forma como são conduzidos influência no desenvolvimento das potencialidades do ser humano (Batista et al, 2013). As vivências de violência intrafamiliar, nas diferentes fases do desenvolvimento humano, podem deixar marcas visíveis e invisíveis no indivíduo (Batista et al., 2013).

O modelo teórico apresentado por Urie Bronfenbrenner (2002), a Teoria Bioecológica do Desenvolvimento Humano, busca a ampliação do entendimento do desenvolvimento humano ao considerar os quatro aspectos inter-relacionados: o processo, a pessoa, o contexto e o tempo. Esse modelo conceitua as expressões comportamentais como produtos da interação genética e do ambiente, apresentando uma proposta para formar conceitos acerca dos contextos do desenvolvimento, com a organização de sistemas de quatro níveis que, progressivamente, se tornam mais amplos: microssistema, mesossistema, exossistema e macrossistema (Bronfenbrenner, 2002).

É no microssistema que o indivíduo desenvolve um conjunto de papéis sociais primários com apreensão dos valores padronizados pela sociedade como base para o seu desenvolvimento. O mesossistema envolve a participação ativa da pessoa e a interação com outros ambientes, como, por exemplo, as relações entre casa e trabalho. Já o exossistema caracteriza-se por ambientes fora do convívio familiar, ainda que, a experiência de vida da pessoa influencia os demais membros do grupo e o macrossistema constitui-se como o mais amplo dos sistemas, pois, engloba padrões de organização social, cultural e ideológica (Bronfenbrenner, 2002; Batista et al., 2013).

Para o planejamento de uma atenção integral às mulheres vítimas de violência intrafamiliar é necessário uma atuação interdisciplinar, com desenvolvimento de ações estratégicas para identificação da demanda, acompanhamento e/ou resolução. Assim como é importante ampliarmos os conhecimentos sobre as vivências de diversas formas de violência, visando o planejamento de intervenções que atendam às necessidades dessas mulheres. No presente estudo, buscamos compreender a partir da perspectiva bioecológica as diferentes vivências de violência e suas repercussões para a vida de uma mulher.

\section{MÉTODO}

Trata-se de um estudo qualitativo em que foi utilizado o estudo de caso. Esse tipo de estudo é usado em muitas situações, pois possibilita ampliar o conhecimento dos fenômenos individuais, grupais, organizacionais, sociais e políticos. A pesquisa de estudo de caso surge do desejo de compreender fenômenos sociais complexos, como, por exemplo, a violência (Yin, 2015). Participou uma mulher com história de violência intrafamiliar, atendida em um Centro de Referência e Atendimento à Mulher (CRAM), localizado na região norte do estado do Paraná. Este serviço é responsável por prestar assistência e desenvolver políticas 
públicas que atendam as demandas específicas das mulheres, sobretudo vítimas de violência. Entretanto, esta pesquisa foi desenvolvida a partir de um estudo de caso único para investigação de um fenômeno em profundidade (Yin, 2015), com a finalidade de compreender a violência e suas repercussões para a vida de uma mulher.

Para a coleta de dados utilizamos entrevista semiestruturada, com questões previamente elaboradas sobre o foco de interesse do estudo. A entrevista foi agendada por meio de contato telefônico com a participante. No dia e horário combinado, a pesquisadora apresentou os objetivos da pesquisa e a participante assinou o Termo de Consentimento Livre e Esclarecido (TCLE). A entrevista foi gravada, realizada em encontro único, em sala reservada e com privacidade na instituição, com duração de duas horas. Os dados foram organizados mediante transcrição e submetidos à análise temática indutiva. A partir da leitura detalhada do material transcrito foram feitos recortes e gerados códigos iniciais. $\mathrm{Na}$ sequência, foram agrupados os temas de acordo com a similaridade, gerando diferentes temas potenciais. Esses temas foram revisados e relacionados às questões deste estudo (Braun \& Clarke, 2006).

O projeto de pesquisa obteve aprovação do Comitê Permanente de Ética em Pesquisa do Centro Universitário de Maringá (Cesumar-COPec), conforme Certificado de Apresentação para Apreciação Ética - CAAE número 0319.0.299.000-09.

Para preservar a identidade da participante foi utilizado nesse estudo um nome fictício. Antônia de 59 anos, tem ensino médio incompleto, pertencente a classe social $D$, segundo os critérios da Associação Brasileira de Empresas de Pesquisa (ABEP, 2012), viúva há sete anos e com dois filhos dessa união. Nasceu e foi criada na zona rural do interior do estado do Paraná-PR. Seus pais trabalhavam com agricultura familiar, ela e seus irmãos tiveram uma infância marcada por situações de vulnerabilidade social e econômica. Vivenciou diferentes formas de violência interpessoal, em que os abusos físicos, psicológicos e sexuais transcorreram diferentes fases do seu desenvolvimento.

\section{RESULTADOS}

As situações de violência vivenciadas por Antônia, no contexto doméstico, que transcorreram diferentes fases do seu desenvolvimento, geraram repercussões para sua vida, afetando, sobretudo sua saúde. No entanto, os atendimentos da Antônia em um serviço especializado, destinado ao acolhimento e atendimento humanizado de mulheres em situação de violência, iniciou-se a partir de um acompanhamento psicossocial, decorrente da vivência de um estupro por desconhecido na fase adulta.

A partir da análise do relato da Antônia, construímos duas unidades temáticas: "uma vida de violência" e "violência e as repercussões para a saúde da mulher", que foram descritas e exemplificadas com trechos extraídos do relato da participante. 


\section{Uma vida de violência}

A partir do relato da Antônia identificamos vivências de situações de violência, com abusos físicos e psicológicos. Essas situações ocorreram em diferentes fases do desenvolvimento da participante. Na sua infância e adolescência, presenciou e vivenciou cenas de violência, sobretudo abusos físicos na relação de seus pais e que se estendia para os filhos. Antônia relatou que no relacionamento conjugal dos pais havia brigas, que estavam relacionadas ao uso problemático de álcool pelo pai. Antônia descreveu ainda que essas experiências de violência a levaram a deixar a casa da família.

Eu fugi de casa com 12 anos. Eu nasci e fui criada no sítio e desde que me conheço por gente, via minha mãe sangrando todos os dias. Meu pai bebendo e batendo. Um dia, peguei um embornal, coloquei umas roupas de saco de açúcar dentro e vim morar nessa cidade.

Na infância, adolescência e fase adulta, Antônia, vivenciou situações de violência, sobretudo no ambiente doméstico. Ela relatou ter conhecido o pai de seus filhos, em uma situação de vulnerabilidade social, quando deixou a casa da família e mudou-se para outra cidade. Sem ter onde morar, aceitou o trabalho como doméstica na casa dele. Durante 18 anos de convivência, Antônia, foi vítima de diversos episódios de violência, incluindo estupro, abusos físicos e psicológicos.

Cheguei aqui, fui ficar no parque de exposição. Assim, conheci uma pessoa e fui trabalhar na casa dele. Desse trabalho resumiu no que hoje eu falo que foi um estupro, porque eu não queria ter relações com ele, não queria ter nada com ele. Me pegou na marra... Eu era como uma doméstica, ele levava a amante para encher a pança e o que sobrava para mim era serviço e pancada. Fiquei 18 anos morando com ele e apanhando em toda parte dos olhos e do rosto.

As dinâmicas familiares e sociais, disfuncionais, vivenciadas pela Antônia foram identificadas nos seus relatos. A violência doméstica foi relatada em diferentes momentos, envolvendo o filho, ela e o parceiro. Antônia, descreveu os abusos físicos do parceiro contra o próprio filho, inclusive com uso de objetos como cinta e agressões entre ela e o parceiro. Além disso, identificamos um processo de transmissão geracional do comportamento violento, envolvendo o filho de Antônia e do parceiro, como autor e vítima da violência.

Tive meu filho com 13 anos, quando meu filho fez três meses, tanto eu como meu filho viramos saco de pancada, a gente apanhava todos os dias. Ele pegava meu filho com três meses e deixava todinho machucado de fivela de cinta e depois enfiava ele dentro de uma bacia de salmoura. Gente que sofrimento, pensa.

Ele veio me deu um tapão na cara que eu rodei e cai no chão, mas besta foi ele, porque quando eu cai, tinha quatro cadeiras de madeira, parece que o cão encostou em mim, eu dei uma cadeirada nele e o sangue esguichou pensa numa pessoa que ficou louca ... eu queria matar, queria acabar com a vida dele, ele 
vinha com a faca e mandava a faca em minha direção, ele batia com a faca e eu com a cadeira na cabeça dele. Até hoje eu tenho a mesa toda picotada.

Tive uma briga com meu filho mais velho, ele vinha para cima de mim com um pau. Uma vez ele me deu um tapão na minha cara, nesse dia eu quebrei o braço dele.

A vivência de situações de violência sexual ocorreu nas diferentes fases do desenvolvimento de Antônia. Na infância, vivenciou abuso sexual, cujo agressor foi o tio, uma pessoa com vínculo de parentalidade. Nesse contexto, Antônia, relatou que foi punida pela mãe, com abusos físicos. Na adolescência, vivenciou uma situação de estupro por um homem que se tornou, ainda que contra a vontade de Antônia mas com o consentimento dos pais dela, seu parceiro íntimo assumindo o filho que ela gerou do estupro que sofreu. Na fase adulta, a participante relatou ter vivenciado duas situações de estupro, uma em que o agressor foi o parceiro e outro, cujo agressor era um homem desconhecido.

Com oito anos, o irmão da minha mãe pegava o treco dele e ficava esfregando em mim. Ele tinha uns 22 anos, era meu tio. Ele ficava com essa cachorrada, Um dia minha mãe viu meu tio abusando de mim eu levei uma surra de ficar roxa. Eu falei para ela: mãe você tinha que bater no seu irmão, não bater em mim.

Eu tinha 12 anos quando fui trabalhar na casa dele. Nesse trabalho, eu sofri um estupro, porque eu não queria ter relações com ele, não queria ter nada com ele, mas me pegou na marra...

Com medo de morrer eu me propus a uma coisa nojenta que até hoje a hora que eu penso me dá uma revolta...

A vivência de uma situação de estupro, na fase adulta da Antônia, ocorreu em área pública. Nesta circunstância, Antônia relatou sofrer abusos físicos e psicológicos, manifestados por facadas, puxões de cabelo, mutilação genital, xingamentos, ofensas e ameaças.

Quando eu cheguei onde eu iria virar, ele encostou a moto, com a faca no meu pescoço e falou para eu ficar quieta, furou o meu pescoço, ele me deu uma facada no peito e fiquei toda marcada... tinha vários carros passando, mas ninguém viu, a impressão que dava é que ele estava me abraçando. Ele parou a moto, me arrastou pelo cabelo, entrando no mato, me jogou no chão, sentou no meu peito, eu queria morrer. Veio com aquele troço (pênis) fedorento enfiando na minha boca... Ele pintou e bordou ele fez tudo o que ele quis, pegava o cabo da faca e ficava socando na minha vagina, fiquei com a minha vagina enorme de inchada. Tenho certeza que ele me largou lá no mato, porque ele tinha certeza que eu estava morta. Ele me furou inteirinha com faca. Eu lembro que ele me deu muito murro e ele falava cala boca vagabunda, grita biscate (choro). 


\section{Violência e as repercussões para a saúde da mulher}

Nesta unidade temática, identificamos as repercussões das vivências de situações de violência, sobretudo para a saúde de Antônia. As duas gestações descritas pela participante, foram decorrentes de situações de violência sexual, que ocorreram no contexto doméstico. Na adolescência, com 12 anos de idade, teve a primeira gravidez, como consequência de um estupro, praticado pelo dono da casa em que morava e trabalhava, ou seja, no contexto doméstico. Esta circunstância, fez com que Antônia permanecesse em um contexto de vulnerabilidade, contribuindo para vivência de outras situações de violência. $A$ segunda gravidez ocorreu na fase adulta da Antônia, também decorrente de uma situação de estupro praticado pelo mesmo homem, pai do seu primeiro filho.

Fui violentada e já engravidei. Engravidei com 12 anos. Ele tinha 57 anos, era separado da primeira esposa e tinha 4 filhos...Meus pais naquele tempo antigo... meu pai falou para ele que eu tinha me perdido por lá, ele teria que me assumir. Eu tive que voltar para a casa dele (estuprador).

Nós dormíamos em quartos separados, um dia a irmã dele veio fazer uma visita e tive que dormir no mesmo quarto que ele. Fazia 10 anos que eu não tinha relação com ele nem com ninguém. Ele veio deitou em cima, eu não podia gritar, porque estava com a casa cheia de visitas. Não podia berrar e me aguentei. Parece que Deus foi tão cruel comigo que eu engravidei de novo. Quando meu filho caçula nasceu, o mais velho tinha 17 anos.

Antônia relatou vivências de violência, no contexto doméstico, com abusos físicos, manifestados por chutes e pontapés. Em uma dessas situações de violência, houve a necessidade de atendimento pela equipe de saúde, em um serviço de urgência e emergência, inclusive com intervenção cirúrgica.

Eu estava sentada fazendo xixi, ele chegou e me deu um chute tão violento que o bico do sapato pegou na minha vagina, foi arrebentado tudo por dentro e o sangue esguichou, estourou meu útero com um chute. Precisei fazer cirurgia, o médico disse que eu não poderia mais engravidar.

Além das diversas situações de violência no contexto intrafamiliar, Antônia também foi vítima de uma situação de estupro, em que o agressor era desconhecido. Como consequência dessas vivências de situações de violência Antônia desenvolveu problemas de saúde, com sentimentos de angústia, tristeza, raiva, dificuldades para dormir, afetando ainda os aspectos psicossociais.

Foi a primeira vez que eu vi aquele homem, mas se eu ver a cara dele hoje eu sei quem ele é. É uma coisa que grava na sua memória. Falei para psicóloga que por isso eu estou dormindo muito mal, uma hora e meia na noite...Eu falo pra Deus: eu quero morrer, quero tirar minha vida, de tanto ódio que eu tenho daquele homem. 


\section{DISCUSSÃO}

A discussão desse estudo tem como objeto as vivências de diferentes situações de violência e suas repercussões para a saúde da Antônia. Essas vivências transcorreram as diferentes fases da sua vida e compuseram espaços de vulnerabilidade com situações adversas ao desenvolvimento saudável. Existem elementos importantes nos vínculos familiares e no cuidado e proteção da criança, relacionados aos aspectos afetivo e comportamental, que em circunstâncias como violência intrafamiliar, se configuram situações negativas ao desenvolvimento infantil sadio (Silva, Maftum, \& Mazza, 2014).

No presente estudo, identificamos no microssistema em que Antônia estava inserida, situações de violência intrafamiliar. Nesse contexto, Antônia, vivenciou durante a infância e adolescência violências, manifestadas por abusos físicos, psicológicos e sexuais, cujo os agressores possuíam vínculo parental. Entende-se que a infância e a adolescência são fases do desenvolvimento humano, em que a vulnerabilidade aos agravos da saúde e a fatores econômicos e psicossociais se potencializam (Oliveira et al., 2015). É no ambiente familiar que se estabelece as relações primárias, representada por uma unidade social e comportamental interdependente entre os seus membros, ou seja, a forma de agir de um interfere no comportamento do outro, sendo assim, a conduta violenta de um para com outro tem repercussões significativas nas vidas dos envolvidos, como identificado no caso da Antônia (Batista et al., 2013).

A literatura mostra que a violência gerada no âmbito doméstico traz em suas origens processos multicausais, incluindo o abuso de álcool e outras substâncias psicoativas e a distribuição desigual de autoridade e poder entre os membros da família sob a perspectiva patriarcal, conforme identificamos nos relatos da participante (Batista et al., 2013; Ferreira \& Lopes, 2017). Nesse contexto, a violência sexual é uma das expressões da violência doméstica de gênero, em que as situações de abuso sexual na infância podem ser especialmente ameaçadoras, aumentando o risco de repetir o ciclo de novos abusos com as próximas gerações (Sufredini, Moré, \& Krenkel, 2016). Antônia vivenciou situações de violência sexual nas diferentes fases do seu desenvolvimento. Em situações de abuso sexual, de modo geral, as meninas revelam o abuso a uma figura afetiva como a própria mãe e avós. A maioria das mães não têm ciência de que tal abuso ocorre, ao tomarem conhecimento são as que mais denunciam a violência e promovem ações protetivas (Azevedo \& Pereira, 2016). Por outro lado, existem mães que apresentam sentimentos de ambivalência e de descrédito frente ao relato das filhas e não providenciam suporte de proteção, como no caso da Antônia. Normalmente, essas reações emocionais estão associadas à necessidade de preservar o vínculo afetivo com o suposto abusador e à dificuldade para enfrentar mudanças na família, resultantes da denúncia. Como consequências da revelação do abuso sexual, as mães vivenciam sentimentos de culpa por não terem protegido as filhas, além de sofrimento, dor, 
tristeza, vergonha, choque, angústia, desespero, desconfiança e embotamento afetivo, causando prejuízos para a saúde das mães e das vítimas (Sufredini et al., 2016). Existem também mães que não compreendem o papel de apoio emocional e protetivo que a família desempenha no desenvolvimento de crianças e adolescentes, com a revelação do abuso sexual elas se distanciam emocionalmente das filhas, não oferecem suporte, dão pouca importância ou minimizam a situação de abuso (Sufredini et al., 2016).

As vivências de situações de violência no contexto familiar são marcadas por características como vulnerabilidade, dependência emocional ou econômica dos envolvidos, situações de abuso na família de origem e relação sociedade-família de forma adversa ao desenvolvimento humano (Azevêdo \& Pereira 2016; Ferreira \& Lopes, 2017). Neste estudo, a violência intrafamiliar também está associada à gravidez na adolescência, fenômeno já descrito na literatura (Fernandes, Santos, Esteves, Vieira, \& Sousa Neto, 2017). No caso de Antônia, as duas gestações foram consequência da violência sexual, que ocorreram no contexto doméstico, em que o autor convivia com a vítima em uma relação de poder e submissão relacionada ao gênero feminino. Este microssistema retrata um ambiente que apresenta pouca abertura ao diálogo e evidencia a naturalização da violência nas relações. $A$ desigualdade e a submissão estão presentes nas relações interpessoais hierarquizadas estabelecidas na família de origem e, nesse contexto, podem se tornar referência para o novo grupo familiar, como no caso de Antônia. Dessa forma, perpetua a posição silenciosa do abuso e da manutenção de situações de risco da violência embutida nas relações familiares, sobretudo, relacionada às questões de gênero (Lordello \& Costa, 2014).

Para compreender Antônia ressalta-se que em seu microssistema familiar e nas interconexões com outros contextos em que vivia, ela não pode contar com uma rede de apoio. Bronfenbrenner (2002) chama a atenção para a importância do papel significativo dos pais ou de quem ocupa esse lugar em oferecer um desempenho efetivo no relacionamento com seus filhos, oferecendo apoio físico e emocional para eles, diferente do caso de Antônia, que não recebeu esse tipo de apoio dos seus pais. Especificamente, com relação à violência intrafamiliar há uma complexa interação de fatores individuais, relacionais, sociais e culturais (Bronfenbrenner, 2005). Considerando a realidade de Antônia a pouca idade, a presença de diferentes manifestações de violência da família primária, a ausência de rede de apoio social relatada pela colaboradora contribuíram para que ela não contasse ou procurasse ajuda e assistência especializada anteriormente e, ficando exposta à violência por tanto tempo.

A gravidez decorrente da violência sexual traz repercussões para a vida das gestantes, envolvendo aspectos sociais, contextos e relações, ambivalência de sentimentos de culpa e de vergonha, mudanças no processo de rejeição/ aceitação empreendidos pela mulher durante a gravidez para a vinculação com o bebê (Lordello \& Costa, 2014). Além disso, a violência contra a mulher extrapola os limites jurídicos e estende-se para território da saúde, 
sobretudo da saúde mental, como nos casos de vítima de estupro por autor desconhecido (Silva \& Vagostello, 2017). Antônia, na fase adulta, vivenciou uma situação de estupro por autor desconhecido, com repercussões para sua saúde mental. Como descrito na literatura, ela apresenta sintomas depressivos e distúrbios de ansiedade, dificuldades para dormir, principalmente de estresse pós-traumático relacionados às vivências de violência (Silva \& Vagostello, 2017).

Essas circunstâncias remetem a necessidade de aperfeiçoar tecnologias de cuidado, que enfoquem as relações familiares e à proteção de crianças e adolescentes vítimas de violência intrafamiliar, assim como desenvolver estratégias para identificação e enfrentamento da violência, visando a promoção do desenvolvimento humano (Silva et al., 2014). Intervenções primárias de prevenção à violência são importantes, sobretudo, para romper o ciclo da violência. Dentre as ações descritas na literatura como facilitadoras de prevenção à violência intrafamiliar, estão: a atuação dos agentes comunitários de saúde, o vínculo com a comunidade e a parceria existente com as escolas (Oliveira et al., 2015; Martins et al., 2017).

Por outro lado, existem fatores que dificultam essa prática, tais como: o não acesso às famílias que apresentam receio diante da possível interferência do serviço de saúde em seu ambiente doméstico e o fato de não haver um órgão, uma equipe ou capacitação necessária para os profissionais atuarem de forma mais segura e efetiva em suas ações de investigação e confirmação dos casos suspeitos, bem como o desrespeito às questões éticas no cotidiano de trabalho, quando os profissionais realizam a denúncia (Oliveira et al., 2015; Martins et al., 2017). Além disso, existem dificuldades relacionadas ao número de profissionais atuantes na área e a inserção de outros profissionais como psicólogo e assistente social para realizar um atendimento específico (Oliveira et al., 2015; Martins et al., 2017). Sobre Antônia, ela não recebeu atendimento dos serviços de saúde, com ações direcionadas às intervenções primárias de prevenção à violência intrafamiliar, principalmente na infância e adolescência. Na fase adulta, Antônia recebeu apoio fora do ambiente familiar, do CRAM, sendo esse contexto de desenvolvimento o exossistema. Nesse serviço, ela teve acesso às intervenções secundárias, envolvendo segurança pública e justiça, após vivenciar um estupro por desconhecido.

É possível identificar nos relatos da Antônia a influência do macrossistema no seu desenvolvimento, marcado por situações de vulnerabilidade socioeconômica relacionadas aos padrões de organização social, aspectos culturais e ideológicos patriarcais, com nítidas relações de poder entre homens e mulheres, que levaram a às vivências de diversas formas de violência (Bronfenbrenner, 2005; Batista et al., 2013; Silva \& Vagostello, 2017). Além disso, como identificado no caso de Antônia, a carência de ações primárias de prevenção da 
violência intrafamiliar, que perpassa pelas políticas públicas, formação dos profissionais e aspectos culturais, são fatores também relacionados ao macrossistema.

Analisar os casos únicos de violência a partir da perspectiva bioecológica, como o de Antônia, possibilita ampliar o conhecimento sobre um fenômeno complexo, como a violência intrafamiliar e suas repercussões para a vida do indivíduo. No modelo bioecológico é considerado as experiências vividas nas diferentes fases do desenvolvimento humano, bem como as expressões comportamentais relacionadas às interações biológicas e ambientais. $A$ partir dessas informações é possível planejar ações direcionadas a cada sistema (microssistema, mesossistema, exossistema e macrossistema), considerando as necessidades individuais, do grupo familiar e social, com intuito de promover o desenvolvimento humano (Bronfenbrenner, 2005; Batista et al., 2013).

Entende-se que analisar um caso único de violência intrafamiliar não permite a generalização das interpretações do estudo. No entanto, há evidências científicas de fatores comuns nas situações de violência intrafamiliar como, por exemplo, desemprego, condições de pobreza ou empobrecimento, valores culturais que justifiquem condutas violentas como o patriarcal, conflitos conjugais, problemas psicológicos e afetivos, alcoolismo, falta de serviços básicos, como creches, escolas e habitações conforme a necessidade da população (Azevêdo \& Pereira 2016), alguns desses corroboram no caso de Antônia. Assim, a análise de caso único possibilita conhecimento mais aprofundado sobre o fenômeno e suas circunstâncias, por exemplo, no caso de Antônia identificamos a falta de prevenção primaria da violência, com elementos que podem contribuir para a construção de ações de prevenção direcionadas aos sistemas do modelo bioecológico.

\section{CONSIDERAÇÕES FINAIS}

O presente trabalho possibilitou compreender a vivência de situações de violência intrafamiliar e sexual a partir do relato de Antônia, assim como conhecer os impactos para a saúde da mulher. Além disso, permitiu aproximar-se da complexidade que envolve múltiplas vivências de violência. Mas as limitações do estudo devem ser consideradas no campo conceitual e metodológico, pois, trata-se de um estudo de caso único, que impossibilita a generalização dos dados, apesar de permitir o aprofundamento nesse tema complexo, que é a violência intrafamiliar. Estudos sobre essa temática também podem ser desenvolvidos sob a perspectiva de outros modelos teóricos como, por exemplo, a partir do referencial teórico de análise do discurso.

A violência intrafamiliar tem impactos na vida do indivíduo com diferentes repercussões a depender do momento do ciclo vital em que ocorre. A história de Antônia denuncia a necessidade de aprimorar o atendimento nos serviços de saúde para detectarem situações de violência e oferecerem o suporte necessário às vítimas, bem como acesso a 
outros serviços como assistência social e justiça para medidas protetivas que se fizerem necessárias, favorecendo recursos físicos e emocionais para lidar e sair da situação de violência.

A compreensão da história de Antônia nos permite refletir sobre a necessidade de cuidados efetivos às mulheres vítimas de violência e a partir disso traçar estratégias com equipes multidisciplinares, envolvendo os diferentes dispositivos públicos, por meio de articulação intersetorial para atender a complexidade que as situações de violência demandam.

\section{REFERÊNCIAS}

Associação Brasileira de Empresas de Pesquisa. (2012). Critério de classificação econômica Brasil. Recuperado em 15 de outubro de 2017, de http://www.abep.org/novo/Content.aspex?ContentID=301.

Azevêdo, J. L., \& Pereira, M. F. A. (2016). Urgências psicológicas no cuidado às mães em casos de abuso sexual intrafamiliar. Estudos de Psicologia, 21(3), 337-347. Recuperado em 05 de agosto de 2018, de: http://www.scielo.br/pdf/epsic/v21n3/1413-294X-epsic-2103-0337.pdf.

Batista, J. M. S., Trigueiro, T. H., Lenardt, M. H., Mazza, V. A., \& Labronici, L. M. (2013). O modelo bioecológico: desvendando contribuições para a práxis da enfermagem diante da violência doméstica. Escola Anna Nery, 17(1), 173 - 178. Recuperado em 01 de agosto de 2018, de: http://www.scielo.br/scielo.php?script=sci_arttext\&pid=S141481452013000100024 .

Braun, V., \& Clarke, V. (2006). Using thematic analysis in psychology. Qualitative Research in Psychology, 3(2),77-101. Doi: 10.1191/1478088706qp063oa.

Bronfenbrenner U. (2002). A ecologia do desenvolvimento humano: Experimentos naturais e planejados. São Paulo: Artmed.

Bronfenbrenner, U. (ed.) (2005). Making human beings human: Bioecological perspectives on human development. Thousand Oaks: Sage Publications Ltd.

Camicia, E. G., Silva, S. B., \& Schmidt, B. (2016). Abordagem da transgeracionalidade na terapia sistêmica individual: um estudo de caso clínico. Pensando Famílias, 20(1), 6882. Recuperado em 03 de outubro de 2018, de:

http://pepsic.bvsalud.org/scielo.php?script=sci_arttext\&pid=S1679494X2016000100006.

Fernandes, M. M. S. M., Santos, A. G., Esteves, M. D. S., Vieira, J. S., \& Sousa Neto, B. P. (2017). Fatores de riscos associados à gravidez na adolescência. Revista de Enfermagem da UFPI, 6(3),53-8. Recuperado em 20 de outubro de 2018, de: http://www.ojs.ufpi.br/index.php/reufpi/article/view/5884/pdf

Ferreira, R. M., Vasconcelos, T. B., Moreira Filho, R. E., \& Macena, R. H. M. (2016). Características de saúde de mulheres em situação de violência doméstica abrigadas em uma unidade de proteção estadual. Ciência \& Saúde Coletiva, 21(12), 3937-3946. 
Recuperado em 06 de outubro de 2018, de: http://www.scielo.br/pdf/csc/v21n12/14138123-csc-21-12-3937.pdf.

Ferreira, T. B., \& Lopes, A. O. S. (2017). Alcoolismo, um caminho para a violência na conjugalidade. Revista UNIABEU Belford Roxo, 10(24), 95-110. Recuperado em 03 de outubro de 2018, de: http://revista.uniabeu.edu.br/index.php/RU/article/view/2527.

Justino, Y. A. C., Cotonhoto, L. A., \& Nascimento, C. R. R. (2017). A perspectiva de mães a respeito das relações parentais diante de um contexto de violência doméstica contra mulher. Pesquisas e Práticas Psicossociais, 12 (3), 1-20. Recuperado em 06 de outubro de 2018, de: http://pepsic.bvsalud.org/pdf/ppp/v12n3/04.pdf.

Lordello, S. R., \& Costa, L. F. (2014). Gestação decorrente de violência sexual: um estudo de caso à luz do modelo bioecológico. Contextos Clínicos, 7(1), 94-104. Recuperado em 20 de outubro de 2018, de:

http://pepsic.bvsalud.org/scielo.php?script=sci_arttext\&pid=S1983-34822014000100010.

Martins, E., Rato, M., \& Marques, E. (2017). Violência familiar: conceitos, impacto e intervenção dos profissionais de saúde. Egitania Sciencia, 11(21), 1-16. Recuperado em 05 de setembro de 2018, de:

http://bdigital.ipg.pt/dspace/bitstream/10314/4174/1/ermelindam_169a.pdf.

Oliveira, A. M. N., Marques, L. A., Silva, P. A., Prestes, R. C., Biondi, H. S., \& Silva, B. T. (2015). Perception of healthcare professionals regarding primary interventions: preventing domestic violence. Texto \& Contexto, 24(2), 424-31. Doi: 10.1590/010407072015000092014.

Silva, D. I., Maftum, M. A., \& Mazza, V. A. (2014). Vulnerabilidade no desenvolvimento da criança: influência dos elos familiares fracos, dependência química e violência doméstica. Texto \& Contexto Enfermagem, 23(4), 1087-1094. Recuperado em 06 de outubro de 2015, de: http://www.scielo.br/pdf/tce/v23n4/pt_0104-0707-tce-23-0401087.pdf

Silva, E. P., \& Vagostello, L. (2017). Intervenção psicológica em vítimas de estupro na cidade de São Paulo. Arquivos Brasileiros de Psicologia, 69(3), 183-198. Recuperado em 03 de outubro de 2018, de:

http://pepsic.bvsalud.org/scielo.php?script=sci_arttext\&pid=S1809-52672017000300013.

Stefanini, J. R., Scherer, Z. A. P., Scherer, E. A., Cavalin, L. A., \& Guazzelli, M. S. (2015). Adolescentes com transtorno de déficit de atenção com hiperatividade e exposição à violência: opinião dos pais. Revista Latino-Americana de Enfermagem, 23(6),1090-6. Recuperado em 03 de setembro de 2017, de:

http://www.scielo.br/pdf/rlae/v23n6/pt_0104-1169-rlae-23-06-01090.pdf.

Sufredini, F., Moré,C. L.O.O., \& Krenkel, S. (2016). Abuso sexual infanto-juvenil na perspectiva das mães: uma revisão sistemática. Contextos Clínicos, 9(2), 265-278. Recuperado em 06 de outubro de 2018, de: http://pepsic.bvsalud.org/pdf/cclin/v9n2/v9n2a12.pdf.

Yin RK. Estudo de caso: Planejamento e método. 5a ed. Porto Alegre: Bookman; 2015. 
NOTA SOBRE AS AUTORAS:

Jaqueline Rodrigues Stefanini - Doutoranda, Escola de Enfermagem de Ribeirão Preto da Universidade de São Paulo (EERP-USP). E-mail: jaquelinestefanini@hotmail.com.

Berenice Juan-Martínez - Doutora, Professora Investigadora Associada C da Universidad del Papaloapan. Email: berenice75_bjm@hotmail.com.

Débora Tatiane Góes Silva - Mestre, Psicóloga da Clínica Sintaxe Pronto Atendimento Psicológico. E-mail: deboragoes@yahoo.com.br.

Marciana Gonçalves Farinha - Doutora, Docente do Núcleo de práticas Clínicas do Instituto de Psicologia da Universidade Federal de Uberlândia (IPUFU), marciana@ufu.br.

Recebido: 02/02/19.

Aprovado: 05/04/19. 